\title{
EL PACTO COMO ESTRATEGIA DE CONSOLIDACIÓN \\ DE UN ESPACIO ATLÁNTICO: LOS PORTUGUESES \\ Y LOS ÓRGANOS RECTORES DE TENERIFE \\ DURANTE LA UNIÓN IBÉRICA (1580-1640)
}

\author{
Javier Luis Álvarez Santos
}

\section{RESUMEN}

El presente trabajo analiza el papel ejercido por los órganos rectores de la isla de Tenerife en las estrategias de la élite social insular para consolidar la inserción de este espacio en las dinámicas atlánticas, en especial con el entorno luso circundante durante el periodo de la agregación portuguesa a la Monarquía Hispánica. En primer lugar, abordaremos los vínculos que se originaron entre la oligarquía tinerfeńa y los miembros destacados de la comunidad portuguesa en la Isla. Estas alianzas posibilitaron la inserción de los lusos en la administración local y, a su vez, la participación de la élite tinerfeńa en las redes mercantiles portuguesas. En segundo lugar, trataremos las actuaciones del Cabildo en los asuntos relativos al Atlántico portugués como expresión de este pacto.

Palabras clave: Tenerife, portugueses, pacto, élite insular, Atlántico, Cabildo, Administración mediata.

\section{THE PACT AS A METHOD OF STRENGTHENING AN ATLANTIC AREA: THE PORTUGUESE AND THE GOVERNING BODIES OF TENERIFE DURING THE IBERIAN UNION (1580-1640)}

Abstract

The present research article analyses the role of the governing bodies of the island of Tenerife in the strategies of the insular elite to consolidate the insertion of this space in the Atlantic dynamics, especially in the Portuguese environment during the Iberian Union. First, this study address the links that originated between the oligarchy of Tenerife and the leading members of the Portuguese community on the island. These alliances made possible the insertion of the Portuguese in the local administration and, in turn, the participation of the Tenerife elite in the Portuguese mercantile networks. Secondly, as an expression of this pact, the research discuss the actions of the "Cabildo" in matters relating to the Portuguese Atlantic.

Keywords: Tenerife, Portuguese, pact, island elite, Atlantic, Cabildo, local administration. 


\section{UN PACTO ATLÁNTICO ENTRE MIEMBROS DE LA ÉLITE INSULAR}

La situación privilegiada de Canarias en el entorno atlántico, así como el régimen de excepción de que disponían las Islas para participar en el monopolio mercantil americano, atrajeron la llegada de forasteros, ya fueran castellanos $\mathrm{u}$ oriundos de otras comunidades ${ }^{1}$. No obstante, en el caso de los portugueses, esta participación directa en el trato atlántico de la Isla pasaba por la integración en la sociedad insular. Esta asimilación se sustentaba principalmente con la formalización de lazos a través de acuerdos matrimoniales. Estos vínculos otorgaban confianza y estabilidad a las partes implicadas. El matrimonio aseguraba la condición de vecino y de isleño al forastero y, con ello, el acceso a los negocios de la Isla; mientras, para el insular, consolidaba los vínculos con el entorno atlántico del que dependía.

Junto a estos contratos de casamientos, y generalmente vinculados a éstos, los portugueses asentados en la Isla y los tinerfeños utilizaron otro elemento para consolidar esta unión: las administraciones locales insulares. De una parte, la élite local instrumentalizó y dirigió los órganos rectores locales para aprovecharse de las redes y de los contactos de los agentes lusos en la Isla para su beneficio y, en último término, para el de la propia sociedad insular. De la otra, los miembros destacados de la comunidad portuguesa en Tenerife intervinieron en el comercio insular y en las decisiones para la gobernanza de la Isla a través de la mediación de la administración local, siempre y cuando éstos integrasen al territorio insular y a su élite en las redes atlánticas de las que eran partícipes. Por tanto, se forjó un pacto social entre la élite tinerfeña y la portuguesa. Este pacto aseguró el suministro de víveres a la Isla y consolidó la exportación del vino a los mercados circundantes lusos. Además, este compromiso insular repercutió en las relaciones atlánticas transcontinentales. No fue un acuerdo suscrito, sino una alianza natural entre dos grupos de la élite insular. En último término, este pacto condicionaba la supervivencia de los moradores de una ínsula, naturales o foráneos, en el seno de un océano.

El empleo de estas vías para la consecución de la mimetización permitió emparentar a estos lusos con la oligarquía institucional-mercantil y, de este modo, interferir en las decisiones internas de la Isla. Además, imitaron el comportamiento de esta élite local interesada en la explotación de la tierra y en la comercialización de productos de la Isla. Los portugueses lograron intervenir directamente en la producción de azúcares y vinos, así como en su exportación. La novedad de este sistema de integración estribaba en que, en contrapartida a este pacto social, la comunidad lusa aseguraba la agregación de la Isla -y de sus habitantes- a las redes económicas mercantiles atlánticas en las que ellos eran partícipes.

Con este modelo de asimilación, los destacados hombres de negocio portugueses no sólo pretendieron aparentar ser un miembro más de la élite y disfrutar de

\footnotetext{
1 Guimerá Ravina, Agustín: Burguesia extranjera y comercio atlántico: la empresa comercial irlandesa en Canarias, Santa Cruz de Tenerife, Gobierno de Canarias/CSIC, 1985, p. 21.
} 
los privilegios de los individuos más reputados de la sociedad. Sobre todo, buscaban acceder mediante un acuerdo social a las oportunidades económicas que les brindaba la Isla, tanto en la exportación de productos locales como por la situación estratégica de este territorio en relación con el circuito mercantil atlántico.

Esta estrategia dual de la comunidad portuguesa para ratificar su integración, basada en el compromiso local y en la inserción de la Isla en las redes en las que ellos participaban, queda manifestada a través del estudio del comportamiento social de los principales hombres portugueses asentados en Tenerife. Hacia 1564, casi dos décadas antes de la agregación portuguesa a la Monarquía Hispánica, se instaló en Tenerife Pedro Afonso Mazuelos, un portugués natural de Guimarães. Poco sabemos de sus primeros años en la Isla ${ }^{2}$. La documentación del Cabildo menciona por estas fechas varias veces a un individuo como "el portugués»" Por la cronología y las acciones que desarrolla -especialmente abasteciendo a la Isla, empleando para ello las redes mercantiles en las que está integrado, y en ocasiones concediendo créditos al Regimiento-, pensamos que se trata de la misma persona.

Es sintomático que a este individuo le denominen «el portugués». No se trata de una discriminación hacia él, como pudiera acontecer en otro contexto. Tampoco este apelativo incide en su condición de extranjero, a pesar de que nos referimos a una cronología anterior a la Unión Ibérica. Con el empleo del término "portugués», el Cabildo reafirma los vínculos tan relevantes que aporta este sujeto a la Isla.

Estas primeras aportaciones a la sociedad insular convirtieron a este individuo rápidamente en un miembro más de la comunidad local, confirmándose un pacto entre los insulares y el portugués. En 1575, la documentación notarial refiere ya a Pedro Afonso Mazuelos como vecino de Tenerife. Conocemos que, por estos años, poseía casa y diversas propiedades en la Isla. También sabemos que contrajo matrimonio en el territorio insular, aunque ignoramos cuándo fue realizado y si la cónyuge, Juana Blanco, era natural de la Isla ${ }^{4}$. Estas estrategias personales, conforme al derecho, así como en conformidad con los intereses locales, le permitieron mimetizarse rápidamente en la sociedad local. Este proceso de naturalización culminó en el mismo año de 1575, cuando juró como escribano público de Los Realejos por renuncia de Antón de Azoca5.

2 Sobre Pedro Afonso Mazuelos, véase Negrín Delgado, Constanza: «Las mandas piadosas del portugués Pedro Afonso Mazuelos. Su institución y cumplimiento en la iglesia parroquial de Nuestra Señora de los Remedios, a través de las escribanías de La Laguna», en Anuario del Instituto de Estudios Canarios, núm. 41 (1996), pp. 271-324; y Álvarez Santos, Javier Luis: «El portugués Pedro Afonso Mazuelos», en XVIII Coloquio de Historia Canario Americana (2008), Las Palmas de Gran Canaria, Cabildo de Gran Canaria, 2010, pp. 1231-1241.

${ }^{3}$ Como ejemplo, en 1576 el Cabildo compró a «el portugués» cierta cantidad de cal para las fortificaciones. Archivo Municipal de La Laguna, Libros Capitulares, Oficio 1. ${ }^{\circ}$, Libro 14, sf.

${ }^{4}$ Tal vez esta Juana Blanco fuera pariente del mercader flamenco Pedro Blanco, con quien mantuvo intenso trato Pedro Afonso Mazuelos.

${ }_{5}$ Archivo Municipal de La Laguna, Libros Capitulares, Oficio 2. ${ }^{\circ}$, Libro 2, f. 427 v. Cargo en el que es ratificado un año después y que ocupó hasta 1578. Archivo Municipal de La Laguna, t-XIX, 20. 
En menos de una década, este forastero se había convertido en un elemento relevante de la sociedad e, incluso, participó indirectamente a través de sus negocios en las decisiones del Regimiento ${ }^{6}$. Su capacidad de vincular a la Isla con el entorno portugués le convirtieron en un nexo indispensable entre los dos mundos. Véase como ejemplo elocuente que, en 1575, al llegar a Tenerife un poder desde Madeira de dos mercaderes franceses en lengua portuguesa, las autoridades locales pidieron a Pedro Afonso que lo tradujese.

En un breve espacio de tiempo Mazuelos consiguió ser aceptado por la sociedad a través de los mecanismos legales, pero también empleando otros resortes que ayudaron a su naturalización, auspiciada por los miembros de la administración local. Así, en el año 1581 solicitaba este individuo el encabezamiento de las rentas del almojarifazgo, aunque sólo las logró obtener en 1585. Con esta aspiración por controlar las aduanas de la Isla, iniciaba Pedro Afonso Mazuelos una tradición, como sucediera en otras partes de Castilla, de intervención portuguesa en las rentas reales. Tras él, portugueses como Manuel de Oliveira, Luis Lorenzo, Tomás Pereira, etc., hasta la marcha de la Isla de Duarte Enríquez en 1652, controlaron el fisco y las aduanas de Tenerife. Esta supervisión, de las mercancías que entraban y salían, en un territorio tan dinámico como éste otorgaba a estos individuos cierto poder local.

También este interés por el control aduanero estaba estrechamente vinculado al entorno circunatlántico en el que está encajada la Isla. La dependencia del territorio insular de los circuitos mercantiles lusos condicionaba cierto interés por parte de la oligarquía para favorecer la presencia de alguien de confianza y miembro de la vasta red portuguesa para supervisar la actividad mercantil en los puertos insulares.

¿Significaba esto que buena parte de la actividad mercantil estaba dirigida por redes exógenas a la Isla? ¿La actuación de estos individuos principales en Tenerife estaba coaccionada por los intereses de foráneos? Es verdad que quienes intervinieron en estos negocios y controlaron las rentas y las aduanas procedían de fuera de la Isla, con el estímulo y el apoyo de redes portuguesas exógenas, a quienes debían dar cuentas 8 . Pero al mismo tiempo, para que su empresa mercantil tuviera éxito,

${ }^{6}$ Durante la década de los 80 del siglo xvi el Regimiento acude a Pedro Afonso Mazuelos en una decena de ocasiones para que le preste dinero para poder hacer frente a ciertas deudas que mantiene la citada institución. Otras veces, se le solicita que intervenga directamente en el abastecimiento de la Isla; por ejemplo, para traer 1000 fanegas de trigo compradas al vicario de la isla de Gran Canaria. Archivo Municipal de La Laguna, Libros Capitulares, Oficio 2. ${ }^{\circ}$, Libro 4, f. 110 r.

${ }^{7}$ En esta misiva se pedía que se cobrase a un comerciante flamenco todas las mercancías que le pertenecían. Archivo Histórico Provincial de Santa Cruz de Tenerife, leg. 1002, f. 374 v.

${ }^{8} \mathrm{El}$ arredramiento de las rentas reales, en concreto del almojarifazgo, estaba favorecido por los hombres de nación de otros lugares, interesados más en las posibilidades de comercio desde la Isla -legal o ilegal-que en el propio control de los puertos. Además, desde 1641 hasta 1670, estas rentas siguieron estando en manos portuguesas; de Duarte Enríquez Álvarez, desde 1641 a 1650, y de Diego Pereira de Castro desde 1651 a 1670. Anaya Hernández, Luis Alberto: «Los judeoconversos portugueses en Canarias y sus relaciones con el mundo Atlántico Europeo», en IV Centenario del ataque de Van der Does a las Palmas de Gran Canaria (1999): Coloquio Internacional Canarias y el Atlántico, 1580-1648, Las Palmas de Gran Canaria, Cabildo de Gran Canaria, 2001, p. 601. 
era necesario integrar en el beneficio de estas redes a los agentes rectores locales, que, a su vez, eran quienes realmente volcaban a la Isla hacia el comercio exterior.

Fue norma entre estos individuos que pretendían acceder a la administración mediata de Tenerife pactar estrategias matrimoniales con la élite local' ${ }^{9}$. Así, el regidor de origen portugués Gaspar de Espinosa enlazó con la familia Villarroel, los Pereira con los Carrasco y Ayala y los Ocampo. Indirectamente también Cristóbal Salazar de Frías emparentó con la oligarquía. Su hermano Ventura de Frías Salazar había contraído nupcias en su corta estancia en la Isla con la hija del regidor Alonso de Ponte y Cuevas.

Este comportamiento no es contradictorio con la participación de estos individuos en una red mercantil exógena. Más bien se produce una yuxtaposición de intereses. Estos agentes son los elementos conductores que empatan las necesidades de la Isla con el circuito mercantil atlántico y, al mismo tiempo, representan la voluntad de las redes extranjeras. Debemos tener en cuenta que, a diferencia de lo que ocurrió en otras partes de la Monarquía Hispánica, durante todo el siglo XVII no existió un consulado de portugueses, probablemente porque estaban perfectamente integrados en la sociedad local y no necesitaron una justicia privativa.

En esta red atlántica, que tiene como uno de sus sustentos la administración mediata, Luis Lorenzo, de origen luso, es uno de sus miembros más sobresalientes. Al igual que su hermano Andrés Lorenzo, fue nombrado regidor a perpetuidad. Especialmente vinculado a Garachico, como puerto desde donde realizaba buena parte de sus transacciones, fue nombrado alcalde de este lugar en $1607 \mathrm{y}$, un año después, le fue otorgado el título de familiar del Santo Oficio ${ }^{10}$. También dentro del Concejo ocupó el cargo de alcalde de la Mesta (1618). Al mismo tiempo, además de ingresar en el Regimiento, se encargó del control fiscal administrando las rentas reales entre 1611 y 1639. Era un hombre relevante dentro de la sociedad y formaba parte de una importante red, y fue por ello por lo que el Cabildo depositó su confianza en él en varias ocasiones. Fue nombrado proveedor oficial de cosas de la guerra en 1627 , lo que denotaba su relevancia como agente con importantes conexiones que ayudarían a la defensa de una isla en un Atlántico convulso tras la invasión holandesa de Bahía. Asimismo, también se le requirió para el abastecimiento de harina y trigo ${ }^{11}$.

Luis Lorenzo era un miembro activo del comercio complementario entre las Islas. De Lanzarote traía cebada ${ }^{12}$, de Fuerteventura ganado y cueros ${ }^{13}$. Además, su

9 Sobre la organización del Cabildo de Tenerife y las estrategias políticas y familiares de sus miembros durante el Antiguo Régimen, véase Fernández Rodríguez, Lourdes: La formación de la oligarquía concejil en Tenerife: 1497-1629, La Laguna, Instituto de Estudios Canarios, 2013.

${ }_{10}$ Archivo Municipal de La Laguna, R-XII, 75.

${ }^{11}$ En 1631 el Cabildo informa que se le debía a Luis Lorenzo cierta cantidad por harina y trigo que había traído de la isla de Gran Canaria. Archivo Municipal de La Laguna, Libros Capitulares, Oficio $2 .^{\circ}$, Libro 10, f. $71 \mathrm{v}$.

${ }^{12}$ En 1626 comercializaba en la Isla 29 fanegas de cebada en tres partidas por valor de 348 reales.

13 Por ejemplo, en 1619 introdujo de Fuerteventura 353 chivos, diez vacas, siete novillos y tres bueyes; además de 22 cueros de chivos. En 1625 localizamos otra partida de 70 cueros vacunos de 
negocio interinsular no se limitaba exclusivamente al tráfico entre las Islas Canarias. Asimismo, también importaba cueros vacunos de Cabo Verde ${ }^{14}$.

No obstante, sus principales negocios trascendían del ámbito insular macaronésico. La red en la que participaba tenía una estructura internacional. También abastecía a la Isla de trigo procedente de Flandes. En 1620 vendía al capitán Juan de Montesdeoca, vecino de Garachico, 400 fanegas de trigo de Hamburgo por valor de 6759 reales, las cuales habían venido a cuenta Francisco Méndez de Brito, vecino de Lisboa.

Luis Lorenzo se convirtió en un hombre destacado en Tenerife debido a que supo compaginar sus vínculos externos con sus lazos de consanguineidad en la Isla. Actuó conforme a un pacto social suscrito con la élite. Pertenece a una importante red internacional y en el ámbito local es un importante mercader que ostenta el cargo de regidor, controla el circuito de abastecimiento interinsular y, además, controla las rentas.

Este comportamiento suscitará ciertos recelos por entender que el control de la aduana estaba en manos de agentes exógenos. No obstante, su actitud es afín a los intereses generales de la Isla. Por ejemplo, en 1633 se le exigió desde el propio Cabildo que realizara las oportunas visitas a los navíos en el puerto de Santa Cruz, pero Luis Lorenzo alegó que sería nefasto para la Isla tanto registro porque «será más dañoso para las rentas reales y a los almojarifazgos y a los mercaderes muy penoso y sería ahuyentar el trato y comercio con tantas visitas y licencias, y las aduanas siempre impedidas y ocupadas ${ }^{15}$.

Obviamente, tras este alegato se esconden intereses personales -y de la propia red a la que pertenece-, pero no contradice la voluntad general de la sociedad, que está interesada en mantener el trato con el exterior, sea éste realizado de manera lícita o a través del contrabando. Luis Lorenzo, con estas palabras, reproduce fielmente el discurso oficial de la administración mediata respecto a la necesidad imperiosa de mantener a la Isla constantemente vinculada con los principales circuitos mercantiles del Atlántico, aunque ello suponga contravenir las normas del rey.

\section{EL CABILDO COMO INSTITUCIÓN MEDIATA EN LOS ASUNTOS PORTUGUESES}

Los regidores de origen portugués no utilizaron directamente a esta institución para favorecer sus negocios personales provenientes de su red atlántica. Por lo menos no actuaron estos individuos conforme a un partido con intereses estrictamente lusos. Por el contrario, fue la propia institución la que utilizó los contactos

aquella isla por valor de 3510 reales, cuyo flete fue realizado a un maestre de navío vecino de Madeira. Archivo Histórico Provincial de Santa Cruz de Tenerife, leg. 2278, f. 88 r.

${ }_{14}$ En 1626 importaba diez cueros vacunos de aquel archipiélago por valor de 4000 reales.

15 Archivo Municipal de La Laguna, A-XI, 28 y Archivo Municipal de La Laguna, A-XI, 29. 
con estos agentes lusos para su propio beneficio. A través de estos individuos, como ya hemos ejemplificado, se abasteció a la Isla de víveres y mercancías procedentes de Portugal, así como de otras partes del Atlántico.

La comunidad de regidores que conformaban esta administración insular era consciente de que la Isla necesitaba mantener en latencia sus relaciones con los espacios circundantes portugueses, en especial con Madeira y Azores. De estos archipiélagos se concertaba traer trigo ${ }^{16}$. A su vez, Tenerife respondía cuando en aquellos lugares se solicitaba este tipo de víveres ${ }^{17}$. Así, en 1592 llegaba al Cabildo una carta procedente de Madeira informando de la mucha necesidad en aquella isla y pidiendo "ser socorridos y que les den licencia para cargar un navío de trigo ${ }^{18}$. Se trata, en última instancia, de un sistema de solidaridad para garantizar el sustento de una comunidad insular ${ }^{19}$.

Las islas de la Macaronesia, principalmente por ser el lugar más próximo y con fluidas comunicaciones, son el primer territorio de la Monarquía al que se le solicita ayuda en momentos de extrema necesidad. A modo de ejemplo valga referir que en 1621 se le pidió a la isla de Madeira que enviase un médico ${ }^{20}$. No era una novedad, en 1613 la Cámara de Funchal había informado al rey de la falta de médicos en aquella isla, ya que los anteriores habían marchado a Canarias y a Brasil, entre otras razones, por tener un bajo salario ${ }^{21}$. Igualmente, en 1637 el Cabildo tinerfeño insistía en contratar un médico madeirense porque «hay necesidad de médicos, pues no hay hoy más de uno, y la población es grande y los pobres y conventos y hospitales muchos. $\mathrm{Y}$ es necesario que por lo menos haya dos médicos [y] atendiendo a que en esta isla está hoy de presente el doctor Luis Díaz Gutiérrez y ha dado profesión [...] como tal [médico] ha tenido salario en la isla de Madeira, [se le nombra como médico] $\aleph^{22}$.

No obstante, en ocasiones esta cercanía y el trato de vecindad podían suponer un riesgo para la isla de Tenerife. En momentos de propagación de epidemias por el Atlántico el Cabildo tomará medidas para mantener con salubridad a la Isla. En

${ }^{16}$ En 1577 el Regimiento acordó con el mercader francés Mel Oliver que trajese a Tenerife 4000 fanegas de trigo de aquella isla. Archivo Municipal de La Laguna, Libros Capitulares, Oficio 1. Libro 14, f. 234 r.

${ }_{17}$ Por ejemplo, se solicitó traer trigo de Azores en 1627. Archivo Municipal de La Laguna, Libros Capitulares, Oficio 2..$^{\circ}$, Libro 9, f. 183 v.

${ }^{18}$ Archivo Municipal de La Laguna, Libros Capitulares, Oficio 2. ${ }^{\circ}$, Libro 4, f. 101 v.

19 La Cámara de Madeira era consciente de la habitual falta de trigo en Canarias. Por eso, en 1571 informaba esta administración a Su Majestad que aguardaban para remitir cierta cantidad de fanegas de la cosecha de ese año a Lanzarote, por si esta isla tuviese necesidad. Arquivo Regional e Biblioteca Pública da Madeira, Tombo 3. ${ }^{\circ}$ do Registo Geral da Câmara Municipal do Funchal, f. 139 r.

${ }^{20}$ El Cabildo aprovechó que en Tenerife se encontraban algunos de los miembros de la familia de uno de los médicos de aquella isla para solicitar, a través de estos parientes, que viniese a asentarse. Archivo Municipal de La Laguna, Libros Capitulares, Oficio 2. ${ }^{\circ}$, Libro 8, f. 190 r.

${ }^{21}$ Arquivo Regional e Biblioteca Pública da Madeira, Tombo 3. ${ }^{\circ}$ do Registo Geral da Câmara Municipal do Funchal, f. 101 r.

22 Archivo Municipal de La Laguna, Libros Capitulares, Oficio 2. ${ }^{\circ}$ Libro 12, f. 137 v. 
1580, por ejemplo, el Concejo ordenaba que no se admitiesen barcos de Portugal y Madeira ${ }^{23}$. Sin embargo, estas medidas iban en contra de la naturaleza extrovertida de la economía de Tenerife y, sobre todo, contravenían los intereses de la élite insular, involucrada en el comercio internacional. Así, en este mismo año en el que el Cabildo niega la entrada de embarcaciones portuguesas, llegó a la Isla un navío procedente de Madeira. Los regidores, durante las sesiones del Consejo, debatieron si debían aceptar el navío, ya que en él iba parte del sustento de los isleńos y, principalmente, las inversiones de parte de esta oligarquía ${ }^{24}$. Finalmente, la decisión que toman es que sólo se acepten las mercancías si éstas están en buenas condiciones y, si es así, se las entreguen a Pedro Afonso Mazuelos y a Manuel de Caravallo 25 .

Lo mismo ocurre con embarcaciones de otros lugares del ultramar portugués; por ejemplo, de Santo Tomé. En 1628, llegaba a Tenerife un barco procedente de aquella isla "con azúcares y negros», al cual se le obligó a ponerse en degredo porque sus tripulantes habían venido enfermos e, incluso, alguno había fallecido. Sin embargo, una vez que el navío fue visitado por el médico y el cirujano, se acordó levantar dicha prohibición por no tener problemas de salud ${ }^{26}$.

También, como espacio intraatlántico y dependiente de las relaciones que se producen en su entorno, la administración es consciente de los peligros exógenos que pivotaban alrededor de la Isla. Al Cabildo le llegaban noticias de posibles ataques de enemigos en otros lugares cercanos, como el ocurrido en Cabo Verde ${ }^{27}$. Ante estos posibles peligros, las islas de la Macaronesia construyen a partir del sistema complementario un mecanismo colaborativo para mantener a los archipiélagos defendidos de los enemigos basado en el mantenimiento de canales de comunicación. Por ejemplo, en 1585, llegaba en un navío de Madeira una carta del capitán de aquella isla informando de un aviso de Su Majestad en el que prevenía de un posible ataque de los ingleses ${ }^{28}$. $\mathrm{Al}$ año siguiente, también desde Madeira, se recibieron nuevas noticias de guerra referidas a los ingleses. El Cabildo, correspondiendo a estos canales de comunicación, «trasuntó» el aviso y lo remitió a Gran Canaria ${ }^{29}$. De la misma manera, la Cámara madeirense informaba de otros peligros, como la salida de una escuadra turca de Argel en $1618^{30}$.

${ }^{23}$ Archivo Municipal de La Laguna, Libros Capitulares, Oficio 2. ${ }^{\circ}$, Libro 3, f. 30 r.

${ }^{24}$ Años más tarde, ante la posibilidad de contagio por peste por tratar con una embarcación procedente de Viana, el regidor Bernardino Justiniano pedía que antes de impedir el desembarco, primero se hiciese información porque «el sustento de estas islas es el comercio de los navíos que a ella vienen de fuera». Archivo Municipal de La Laguna, Libros Capitulares, Oficio 1. ${ }^{\circ}$, Libro 15, f. 162 r.

${ }_{25}$ Archivo Municipal de La Laguna, Libros Capitulares, Oficio 2. ${ }^{\circ}$, Libro 3, f. 37 r.

${ }_{26}$ Archivo Municipal de La Laguna, Libros Capitulares, Oficio 2. ${ }^{\circ}$, Libro 9, f. 205 v.

${ }^{27}$ En 1583 llegaban noticias al Regimiento acerca de que los corsarios habían saqueado Cabo Verde. Archivo Municipal de La Laguna, Libros Capitulares, Oficio 2. ${ }^{\circ}$, Libro 3, f. 212 r.

${ }_{28}$ Archivo Municipal de La Laguna, Libros Capitulares, Oficio 2. ${ }^{\circ}$, Libro 3, f. 328 r.

29 Archivo Municipal de La Laguna, Libros Capitulares, Oficio 2. ${ }^{\circ}$, Libro 4, f. 12 r.

30 Arquivo Regional e Biblioteca Pública da Madeira, Tombo 3. ${ }^{\circ}$ do Registo Geral da Câmara Municipal do Funchal, f. 119 r. 
Asimismo, de Azores se reciben noticias de peligros en el Atlántico. En 1597 llegaba una carta del gobernador de San Miguel informando para que las Islas estuviesen prevenidas, ya que los ingleses habían ocupado y destruido la isla de Faial ${ }^{31}$.

Las relaciones con el entorno circunatlántico eran esenciales para Tenerife debido al carácter dependiente de la economía insular. La fluidez en este circuito determinaba el porvenir económico de la Isla y, por consiguiente, de sus habitantes. Por tanto, si alguno de los subsistemas atlánticos sufría alteraciones, estos cambios también incidían en la coyuntura local de la Isla. La ocupación de Bahía por los holandeses es el principal ejemplo de las ataduras económicas de las Isla a otros espacios cisatlánticos y las repercusiones que podían conllevar sucesos exógenos al ámbito insular ${ }^{32}$. Las noticias de la toma de este lugar llegaron al Cabildo insular a finales de 1624. Reunido el Regimiento, entendieron éstos las nefastas consecuencias que este acto iba a tener para los isleños, "con lo cual es notable la miseria en que esta isla se halla y los vecinos de ella, pues padecen por no hallar salida a sus frutos». El Cabildo asumía que era una situación excepcional, que iba más allá de la ocupación por los enemigos del monarca de un territorio alejado, equiparable a otros momentos de grandes penurias sufridas por la Isla. Para intentar solventar dichos males, los hombres del Concejo actuaron en conciencia, empleando los únicos recursos disponibles: implorar por el éxito de las armadas de Su Majestad.

... para lo cual acordaron que en esta ciudad para el miércoles día de Nuestra Señora de la $\mathrm{O}$ por la mañana se saque a Nuestra Señora de Los Remedios en procesión general asistiéndola comunidades y pregonando para que todos los vecinos y pendones de oficios y se vaya con toda devoción al convento del señor San Francisco y allí se digan nueve misas cantadas por nueve días con sus plegarias pidiendo el buen suceso de lo dicho...33.

De la misma manera, cuando meses después llegaron noticias del éxito de la empresa, el Cabildo se reunió y trató sobre ello, ya que resultaba un asunto que concernía a la Isla. Era un motivo de alegría «y particularmente para esta isla». Por ello, respondieron de la manera más sentida: «Acordaron que el domingo próximo siguiente se vaya en procesión de la parroquia de Los Remedios a San Francisco al Santísimo Cristo y se haga misa en alzamiento de gracias.... ${ }^{34}$.

La ocupación holandesa, tuvo sus consecuentes repercusiones para el soberano y para los intereses del reino de Portugal. Pero también la toma de Bahía repercutió en la economía de una isla castellana en medio del Atlántico. Tenerife perdía no sólo el principal mercado al que exportaba los vinos, sino la participación

${ }^{31}$ Archivo Municipal de La Laguna, Libros Capitulares, Oficio $1 .^{\circ}$, Libro 18, f. 117 r.

32 Sobre los intereses de los miembros del Cabildo de Tenerife en el mercado brasileńo, véase Rodríguez Yanes, José Miguel: «El cabildo tinerfeño y las relaciones comerciales de Canarias con Brasil en los siglos Xvi y xviı", en Revista de Historia Canaria, núm. 187 (2005), pp. 205-224.

33 Archivo Municipal de La Laguna, Libros Capitulares, Oficio 2. ${ }^{\circ}$, Libro 9, f. 73 r.

${ }^{34}$ Archivo Municipal de La Laguna, Libros Capitulares, Oficio 1. ${ }^{\circ}$, Libro 22, f. 177 r. 
directa en este circuito atlántico brasileño que tenía ramificaciones por la América española, Angola, Cabo Verde, Lisboa o Sevilla. Además, esta pérdida en el trato mercantil con Brasil no repercutía exclusivamente sobre los portugueses en la Isla, ni siquiera sobre el grupo mercantil insular, afectaba a la sociedad en su conjunto, ya que el modelo de explotación del territorio se sustentaba en la producción de vinos y en su exportación.

La importancia de este circuito, además de por los registros mercantiles, la corrobora la actuación del Regimiento. Entre 1580 y 1640, al menos en una treintena de sesiones del Cabildo se aborda el comercio con Cabo Verde, Guinea y, especialmente, con Brasil. En la mayor parte de las ocasiones esta institución actuaba como altavoz de los intereses locales frente a las disposiciones del monarca. Los miembros del Concejo defendían la práxis mercantil de la Isla; aunque contraviniese al derecho, argumentaban que de este circuito económico se beneficiaba también la Monarquía. Sin embargo, esta actitud de la administración mediata chocaba con el ejercicio de otra administración, la del juez de registro de Indias. Era deber del dicho juez el control de las embarcaciones que pasaban por Canarias como territorio de excepción al monopolio castellano, por lo que en teoría quedaban exentas de este registro las posesiones portuguesas de ultramar ${ }^{35}$. Estas tensiones se revelan en los discursos en el Cabildo, en donde sus miembros descalifican al dicho juez y éste, a su vez, se quejaba de las intromisiones de los regidores en su deber de registrar los navíos.

En 1586, el Concejo opinaba sobre la actuación de este funcionario regio, convirtiéndose en la voz de los mercaderes y navegantes que se acercaban a la Isla:

... se quejan todos los señoríos, maestres y pilotos y mercaderes de los navíos que debiendo llevarles por cada registro, tasándolo conforme al dicho arancel, $90 \mathrm{o}$ 100 reales, se convierten en otros tantos ducados y más. Y esto mismo hace en los navíos del Brasil, Guinea y Cabo Verde, por donde hay grandísima mermuración en esta isla causada de las quejas y clamores de los susodichos... ${ }^{36}$.

Así, en el Cabildo continuaban las quejas y en el mismo año expresaban indignados los regidores:

... porque además de los excesivos costos que se llevan por los registros se quejan que los dichos señores jueces les quitan su libertad en el comprar los vinos que han de cargar porque han de ser a su voluntad y lo mismo en el vender las mercadurías que traen que han de ser por su mano y en su casa haciendo demostración en la dicha su casa de las ropas que traen los dichos tratantes y mercaderes ${ }^{37}$.

35 En 1624, el monarca, por cédula real, confirmaba que Brasil, Angola y Cabo Verde no eran Indias, por lo que dividía la escribanía del dicho juzgado en dos. Una para la América española y la otra para las demás partes. Archivo Municipal de La Laguna, Libros Capitulares, Oficio 1. ${ }^{\circ}$, Libro 22, f. 65 r.

36 Archivo Municipal de La Laguna, Libros Capitulares, Oficio 1. ${ }^{\circ}$, Libro 15, f.168 r; Archivo Municipal de La Laguna, R-IX, 36.

37 Archivo Municipal de La Laguna, Libros Capitulares, Oficio 2. ${ }^{\circ}$, Libro 3, f. 355 v. 
En 1600, el gobernador de la Isla apuntaba a que el rey debía procurar solución a esta intromisión, ya que

... por algunas siniestras relaciones de los jueces del juzgado de las Indias les ha dado comisión [para] que los navíos cargan para Brasil, Cabo Verde y Guinea les den registro y asistan a la carga. $Y$ con este registro no les es de en ningún momento porque en las dichas partes no se lo piden ni hay [más] menester que vender sus vinos que llevan y cargan de las mercadurías de la tierra ${ }^{38}$.

Como consecuencia de estos excesos, continúa el gobernador, «no envían los cargadores de Lisboa de esta isla navíos a cargar como lo han avisado a sus agentes «" ${ }^{39}$.

Sin embargo, esta ambigüedad entre los intereses locales y las ambiciones de la Monarquía no era una característica peculiar del archipiélago canario sino de todo el ámbito circunatlántico bajo el dominio ibérico. También la Casa de la Contratación se quejaba de la injerencia de la isla de Madeira en el comercio americano. En 1595, fue remitida una provisión real a don Luis de Benavides, capitán del Presidio, para que procediese contra aquéllos que trajesen navíos de Indias, con oro y plata para aquella Isla, contraviniendo las ordenaciones del monopolio castellano ${ }^{40}$. No fue el único aviso de la Corona a este respecto: en 1628 volvía a advertir a la administración mediata madeirense para que actuase sobre el comercio ilícito que se venía desarrollando desde aquella isla ${ }^{41}$.

\section{LA ADMINISTRACIÓN MEDIATA ANTE LOS SUCESOS RESTAURACIONCITAS}

A partir de la década de los 30 del siglo xvir, con la ocupación de Pernambuco por parte de los holandeses y la subida de aranceles para comerciar con Brasil, la intervención de la Isla en este circuito mercantil irá en retroceso. En realidad, la prohibición de participar sobre este mercado había comenzado a gestarse desde una década antes. En 1621, los oficiales de la Cámara de Funchal habían remitido a Su Majestad unos «apontamentos» para que sólo los naturales de Portugal pudiesen enviar vinos a Brasil, advirtiéndose a través de esta actitud el futuro vitivinícola de Madeira $^{42}$. Aun así, regidores de Tenerife como Cristóbal Salazar solicitaron al Cabildo que se enviase un mensajero a la Corte para que se retomase el poder comerciar

38 Archivo Municipal de La Laguna, Libros Capitulares, Oficio 2. ${ }^{\circ}$, Libro 4, f. 387 v.

39 Ibidem.

${ }^{40}$ Arquivo Regional e Biblioteca Pública da Madeira, Tombo 3. ${ }^{\circ}$ do Registo Geral da Câmara Municipal do Funchal, f. 215 v.

${ }^{41}$ Arquivo Regional e Biblioteca Pública da Madeira, Tombo 5. ${ }^{\circ}$ do Registo Geral da Câmara Municipal do Funchal, f. 50 r.

${ }^{42}$ Arquivo Regional e Biblioteca Pública da Madeira, Tombo 3. ${ }^{\circ}$ do Registo Geral da Câmara Municipal do Funchal, f. 263 r. 
libremente con la América portuguesa, porque si no es así, «su pobreza y necesidad ordinaria [de la Isla] se refuerza el desampararla ${ }^{43}$.

Pero esta crisis derivada de la pérdida del circuito brasileño es sólo la antesala de las nefastas consecuencias de la Restauración, la consecuente pérdida del trato con los tradicionales vecinos de Tenerife. Con la llegada de la noticia de la sublevación, alerta el Regimiento que «este negocio es el más grave y de importancia que puede haber en estas islas porque con el levantamiento de Portugal, no solo queda cerrada la puerta a todo trato, sino a que carezca esta república de todo lo necesario.... ${ }^{44}$.

La actitud del Cabildo es reflejo del pensamiento de los insulares, donde la incertidumbre ante un panorama incierto hace sucumbir a la comunidad ante el miedo. Refiere el Concejo que las Islas se encuentran perdidas con tanto enemigo, por lo que es necesario fortificar Tenerife. Brasil está ocupado por holandeses y Portugal levantado, por lo que sería fácil que estos enemigos ocupasen alguna isla menor y de ahí saltasen a las demás ${ }^{45}$.

Este pánico infundado en la sociedad a una posible ocupación portuguesa deja paso en breve espacio de tiempo a una nueva percepción sobre las consecuencias de la Restauración. La separación portuguesa tuvo graves secuelas para los isleños, si bien no fueron en el ámbito militar. La pérdida de los mercados lusos supuso la salida de la Isla del circuito económico por el que se habían venido basculando las exportaciones e importaciones, asegurando el sustento para los insulares. En mayo de 1641 ya se notaban las consecuencias de esta ruptura de vínculos en el Atlántico. Afirmaba el Cabildo en esa fecha de lo extenuadas que estaban las Islas por la falta de trato con Brasil, su principal mercado, y por la falta de correspondencia con Portugal ${ }^{46}$.

Señala Anaya Hernández que el portugués Duarte Enríquez, después de hecha la postura para el arrendamiento y antes de que se le remataran las rentas, enterado de la sublevación, solicitó se le anulara su oferta, ya que las rentas valdrían mucho menos. El Consejo de Hacienda no aceptó y ordenó se le remataran, aunque indicó que tendría en cuenta sus argumentos para hacer un descuento. Una vez en Tenerife, volvió a insistir sobre el tema y solicitó seis cuentos de maravedís anuales de rebaja, lo que equivalía a una tercera parte ${ }^{47}$.

La independencia de Portugal fue traumática para las Islas. Desde el poblamiento europeo de Canarias, siempre habían mantenido relaciones con su entorno luso. Los isleños no concebían su vecindario atlántico sin una correspondencia con los territorios portugueses. Aún en 1645, Cristóbal Salazar se lamentaba de la pérdida de Portugal. Decía ante el Regimiento:

${ }^{43}$ Archivo Municipal de La Laguna, Libros Capitulares, Oficio 2. ${ }^{\circ}$, Libro 12, f. $210 \mathrm{v}$.

${ }_{44}$ Archivo Municipal de La Laguna, Libros Capitulares, Oficio 2. ${ }^{\circ}$, Libro 13, f. 213 r.

45 Archivo Municipal de La Laguna, Libros Capitulares, Oficio 1. ${ }^{\circ}$, Libro 25, f. 7 r.

46 Archivo Municipal de La Laguna, Libros Capitulares, Oficio 1. ${ }^{\circ}$, Libro 25, f. 19 r.

47 Hernández, Luis Alberto, «El converso Duarte Enríquez, arrendador de las rentas reales de Canarias», en Anuario de Estudios Atlánticos, núm. 27 (1981), p. 379. 
Que es muy público y notorio la gran quiebra y miseria en que esta isla y las demás han venido con la guerra, así del levantamiento de Portugal, con quien tenían gran comercio como de las partes del Brasil que los holandeses han ocupado. Y ha llegado esto a tan miserable estado que si no se procura con mucha brevedad y grandes veras el remedio de este daño, se perderán estas islas y se despoblarán... ${ }^{48}$.

La conmoción por la Restauración en la comunidad insular, al igual que sucediera en otros territorios de la América española, no conllevó una desambiguación inmediata entre las dos identidades: la local, de base castellana, y la foránea, de componente portugués. Como advierte Trujillo para el caso de Buenos Aires, los lazos de integración habían logrado fundirse incluso más allá de esos límites identitarios. En el momento de la sublevación, era imposible realizar una distinción social en la ciudad bonaerense de una élite portuguesa, contrabandista y criptojudía de una castellano-criolla, leal y católica ${ }^{49}$.

A este respecto, Monteiro y Cardim apuntan que estudiar este horizonte hispánico a partir de la simple dualidad entre Portugal y España no es suficiente para explicar la complejidad del escenario que estamos abordando. Hay que tener en cuenta el comportamiento heterogéneo de cada uno de los espacios, en los que, además, intervenían otras naciones, como la inglesa, la francesa o la holandesa, que también tenían intereses en actuar sobre este mundo ibérico ${ }^{50}$.

Sin embargo, después de 1640, como consecuencia de la separación portuguesa, en el Atlántico se comenzaron a dibujar nuevas fronteras, con una demarcación más rigurosa entre los límites territoriales castellanos y portugueses. En Canarias, aunque no se produjese esta delimitación geográfica, se observa la constitución de nuevos lindes. Exteriormente, se quiebran los lazos que unían a las diferentes regiones portuguesas con Tenerife y, especialmente, se advierte un aislamiento del archipiélago canario respecto al conjunto de la Macaronesia. Internamente, en el aspecto social brotaron rápidamente recelos y desconfianza, pero sólo hacia algunos individuos de la comunidad portuguesa como excusa para provocar alteraciones en el ordenamiento local. La identidad portuguesa, en Canarias, se empieza a construir a partir de la Restauración. En concreto, la pérdida del circuito mercantil portugués y la desvinculación de los intereses de los portugueses al beneficio de la sociedad quebraron el pacto que había permitido la asimilación e integración de estos portugueses, hasta el punto de haber sido considerados como un elemento más de la composición social de los insulares. Es a partir de entonces cuando los castellanos

48 Archivo Municipal de La Laguna, Libros Capitulares, Oficio 2. ${ }^{\circ}$, Libro 14, f.150 r.

49 Trujillo, Óscar José: «Integración y conflicto en una elite fronteriza: los portugueses en Buenos Aires a mediados del siglo xviI", en Cardim, Pedro, Freire Costa, Leonor y Soares da Cunha, Mafalda (orgs.), Portugal na Monarquía Hispânica. Dinâmicas de integração e conflito, Lisboa, Centro de História de Além-Mar, 2013, p. 312.

${ }^{50}$ Monteiro, Nuno Gonçalo y Cardim, Pedro: «A centralidade da periferia. Prata, contrabando, diplomacia e guerra na região platina (1680-1806)», en História, histórias, vol. I, núm. 1 (2013), p. 3. 
insulares compondrán en su imaginario una comunidad portuguesa bien definida y cuando se delimitará una frontera identitaria entre ambos grupos.

\section{CONCLUSIONES}

El abordaje de los órganos rectores de la isla de Tenerife nos ha permitido una aproximación a la práctica jurídica local y a las limitaciones efectivas al poder real de un territorio alejado de la metrópoli al tiempo que inserto en el pujante ambiente atlántico.

Con el estudio del discurso de la administración insular, respecto a la integración de Tenerife en el entorno luso, se observa la praxis de los lazos de dependencia de esta isla con las regiones circundantes, en confrontación a las exigencias virtuales de la Monarquía. Se trató, por ende, de una dicotomía de intereses e intenciones en el mundo atlántico. A su vez, tenemos que tener en cuenta que quienes abogaron por este proteccionismo de los intereses locales frente a los requerimientos de la Corte fueron los miembros de una élite insular que conforma el gobierno de la Isla. En definitiva, fueron los máximos interesados en la plena integración del mercado local en la economía doméstica atlántica, legal y de contrabando.

En una sociedad de frontera, dinámica y en constante regeneración, la élite insular aseguraba su posición estratégica en el sistema atlántico agregando a los resortes de poder locales elementos exógenos que conectasen este territorio aislado y dependiente con su entorno económico. En contramedida, los agentes foráneos se beneficiaron de la próspera economía local, tanto de sus productos como también de la internacionalización de la Isla como centro de intercambios.

En este contexto, el Cabildo desarrolló su propia estrategia de defensa con iniciativas proteccionistas respecto a sus intereses mercantiles $-\mathrm{y}$ la de sus propios miembros en el mercado luso de ultramar-. Se trató de una actuación común en beneficio de la Isla para la preservación de los negocios en las plazas portuguesas, pero también para el lucro de los propios regidores insertos en las redes comerciales del Atlántico. 